\title{
The Role of Emotions in Decision-making
}

\author{
Avinash Jagtap ${ }^{1}$, Rajendra Gurao ${ }^{2}$ \\ ${ }^{1}$ Research Scholar, JJT University, Rajasthan, India \\ ${ }^{2}$ Brihan Maharashtra College, Pune, India
}

\begin{abstract}
A good decision making process is expected, and often required, to be free from emotions. It is done in order to ensure that decision-making is objective. There is a strong belief among decision theorists that objective decision making is unbiased and is more likely to produce good results. This paper discusses some possible effects of emotions on decision making. It also discusses an experiment and its outcome, that was conducted to validate or otherwise, the claimed objectively of decision making being free from emotions. The main outcome of the experiment was the finding that decision-makers achieve better performance in decision making if they are able to control the possible biases produced by their feelings.
\end{abstract}

Keywords: emotional information processing, affective influence regulation, affective reactivity, emotion differentiation, partial mediation Model

\section{Introduction}

There are many so-called theories regarding the effect of feelings on decision-making. Slovic (2001) has discussed a very interesting case of cigarette smoking. Cigarette smoking is the leading controllable cause of cancer. The rationality of smoking decision is an example of the difficulty in appreciating the outcomes that are remote in time and change slowly over time. For a long time, beginning smokers were regarded as "Young Economists" who had rationally compared the risks in smoking with the benefits while deciding whether to begin smoking (see viscusi, 1992). Recent research, however, points to a very different reality. This research (Slovic 2001) shows that young smokers act experientially in the sense that they pay little or no attention to risks or the amount of smoking they would be doing. Rather, they are driven by the impulses of enjoying smoking as something new and exciting. It is perceived as a way to have fun with their friends.

A survey made the failure of the experimental system in protecting many young people from the temptation of smoking more evident than anything else could have. The survey had the following question for smokers. "If you had another chance, would you start smoking?" The answer was "no" from 85 percent of adult smokers and nearly 80 percent of young smokers (ages 14-22). What is more interesting is to find that the more individuals perceive themselves to be addicted, the more often they try to quit. Similarly, the more cigarettes they smoke per day, the more likely they are to answer no to this question.

Emotionality has been conventionally perceived as opposite of rationality in management (see Ashforth and Humphrey, 1995; Putnam and Mumby, 1993). Organizations often ask their employees to keep their affective experiences within a neutral range or to express their feeling within the organizational rules (see Hochschild, 1983; Morris and Feldman, 1996). In the field of finance, similarly, investors are instruct to put their feelings under control, implying that they must avoid or suppress strong feelings (see Babin and Donovan, 2000).
There has been an ongoing debate on whether subjective experiences are beneficial or harmful for decision maker (see, Gohm and Clore, 2002). On one side, it is argued that feelings introduce an unwanted bias (see, Shiv, Loewenstein, Bechara, Damasio and Damasio, 2005; Solvic, Finucane, Peters, and MacGregor, 2002) and hence must be properly regulated (see Gross and John, 2003). On the other hand, it is also claimed that feelings play an adaptive role in decision-making (see Damasio, 1994) and therefore benefit personal well-being (see Aspinwall and Taylor, 1997; Fredrickson 2001). Seo and Barrett (2007) claim that they provide evidence in order resolve this debate. They suggest that whether affective feeling are functional or dysfunctional for decision making depends on how people experience these feelings and how they handle them during decisionmaking. The authors further propose that people can experience intense feelings while making decision, and at the same time, regulate the possible bias those feelings can induce. Both of these contribute positively to their performance at decision-making. It is proposed to study the relationship between affect (feeling) and decision-making with help of a stock investment simulation and an experience-sampling procedure.

It is possible to study the relationship between feelings and performance in decision-making in three different ways. One way is to obtain empirical evidence regarding the influence of feelings on a persons performance in decision-making through an experiment that captures the aspect of psychological realism as well as the benefits of experiments. The second ways is to examine the contrasting views presented in the literature, namely the functional and dysfunctional (that is, bias-inducing) roles of feelings in making decisions in a single study design. The third way is to show that the degree of the functional or dysfunctional role of feelings on decision-making also depends predictably on the person involved in making decision. The feelings in this context refer to a prolonged state of mind associated with no specific object as well as discrete emotions such as anger an fear. 


\section{Literature review and Hypotheses}

Two contrasting perspectives of the effect of affective experience on decision-making are found in the literature. One presents feelings as bias-inducing, where it is suggested that people's feelings induce different forms of bias in their decision-making activity, resulting in their decision getting skewed in certain ways. This approach considers feelings to be harmful for the performance in decision-making. There are many ways in which feelings can introduce bias in decision-making. First, contents of the information that the brain retrieves during decision-making can be affected by feelings. For example, people have a tendency to recall only the memories that are consistent with their feelings at the time of recall. Second, feelings can directly affect cognitive judgments that are necessary in decision-making. It is a common experience that momentary feelings influence many social judgments. In other words, people tend to make judgments that are consistent with their feelings at the time of judgment. A third group researchers have found that feelings can directly influence individual choices. It has be found in many studies that people favor short-term enhancements due to intense unpleasant feelings, focusing on the best choice at the moment, even though it is possible to have long-term negative consequences.

The opposite side of the perception proposes the view that treats feelings as facilitator in decision-making. This view proposes that the performance in decision-making may be improved because feelings may facilitate, or even enable, the decision-making process. There are several ways for feelings to facilitate better decision-making. First, affective reaction can often be a core driver of attention and allocation of memory, which are necessary in decision-making if it involves extensive cognitive processes. In this regard, it is suggested that momentary feelings play an important role by shifting attention from less important goals to more urgent goals. Second, it may help in select and prioritize choices relevant to requirements of the situation if one has some feelings. A common dilemma faced by a decision maker is that he is surrounded by infinitely many options, each with its own advantages and disadvantages, making it difficult, or even impossible, specified time frame. Pleasant as well as unpleasant feelings can be used to resolve this dilemma by developing distinct frames of mind that in turn enable and facilitate selective attention and prioritization of options in terms of their relevance to the requirements of the given situation. The human emotional system helps a person to quickly generate and select options by providing immediate affective evaluations of goodness or badness of each option. Finally, there is considerable evidence to show that momentary feelings have an influence on the way in which people process information during decision-making. This ways in turn promote effectiveness of decision-making in specific contexts. For instance, when people have happy feeling, they categorize the stimulus in a broader, more inclusive and flexible fashion. This tendency in turn enhance creativity and hence the performance in complex situations. On the contrary when people have unpleasant feelings, they process information more effort fully, systematically, and in a piecemeal manner. This leads to effective decision making when the need is of accurate, unbiased and realistic judgments.

\subsection{Variation in emotional information processing}

The two contrasting conclusions from research suggests that emotional experience has the potential of both helping and hurting people involved in making important decision. It is now claimed that how emotional feelings influence decisionmaking is determined by how people experience and handle these feelings, whether in functional or in dysfunctional ways. According to this point of view, people differ not only in how they experience feelings, but also in how they handle those feelings. In other words, people differ in the extent to which they pay attention to information conveyed by their feelings and integrate it into their judgment, decision, and behavior. This framework also suggests that the way people experience their feelings and the way they deal with these feelings are separate and conceptually independent processes.

It is contended here that these two contrasting views of the effect of emotions on decision-making focus on two different process at the individual level. The perspective that views feelings as facilitators in decision-making focuses on "how" people experience their feelings, regardless of what they do about those feelings. On the contrary, the perspective that views feelings as something that induces bias focuses on what people "do" about the feelings they experience. Several researchers have found evidence that the bias-inducing effects of feelings disappear as soon as people attribute their feelings to the correct causes. This view, then implies that all experienced feelings need not introduce bias in decisions. As a matter of fact, the effects of feelings depend more on how people handle those feelings while making decisions.

Before we proceed further, it is necessary to introduce some terminology. The degree to which people experience feelings while making decision is called "affective reactivity" (see Larsen, 2000). The degree to which people control the bias-generating influences of their feelings is called "affective influence regulation". We now formulate the hypothesis that these two independently and interactively contribute to more favorable decision-making outcomes. One more term is introduced here: emotion differentiation. It is defined as the degree to which an individual is able to identify, distinguish, and describe specific feelings. The second hypothesis we formulate states that emotion differentiation affects the performance in decision-making positively and indirectly through its effect on affective influence regulation.

\subsection{Decision-making performance resulting from Affective Influence Regulation}

Researchers have found that people regulate their affective experience and its broader consequences in their judgment, choices and behaviors very differently from one another. As such, affective influence regulation is particularly important for decision-making. Forgas and his colleagues (see Forgas, 2000; Forgas and Ciarrochi, 2002) have explained theoretically as to why are how people differ in affective influence regulation. Their argument is that people temporally engage in two types of emotional information processing modes. One of them is open and constructive 


\section{International Journal of Science and Research (IJSR) \\ ISSN (Online): 2319-7064}

Index Copernicus Value (2013): 6.14 | Impact Factor (2015): 6.391

processing, where people extensively and open-mindedly process both affective and non-affective information. However, they are often not aware of their feelings and the possibility that these feelings may induce biases. As a result, there is an extensive and direct infusion of their feelings into their judgments and choices. The other type of processing is more controlled and directed in information processing and hence make the bias-inducing effect is disappear or reverse because people become aware of their affective experience and hence manage it actively. However, people may still differ in the extent to which they shift from the open substantive processing to the controlled and motivated processing of their feelings. This makes people differ in the degree to which their feelings induce biases in their judgments and decisions. We conclude this section by stating the following hypothesis.

Hypothesis 1. People who have higher affective influence regulation achieve higher decision-making performance than people who have lower affective influence regulation.

\subsection{Decision-making performance Affected by Affective Reactivity}

Many researchers have found that people differ regarding how they respond to different emotional cues in their environments. Some people react more to negative environmental conditions than to positive. Some people react more intensely to both pleasant and unpleasant events. We define "emotional intensity" as the magnitude of emotional feelings experienced during decision-making. It is further suggested that emotional experience influences the following three dimensions of task motivation: direction (that is, choice of action), effort (that is, intensity of action) and persistence (that is, duration of action). It is also suggested that the intensity of feelings may generate a sense of urgency for action and may lead people to devote a greater amount of effort to a given task. This effect can occur without their conscious awareness and regardless of whether their feelings are pleasant or unpleasant. An increase in effort due to intense feelings may further lead to better performance in decision-making as long as performance depends on effort. We have therefore formulated the following hypothesis.

Hypothesis 2. Individuals who have higher affective reactivity perform better in decision-making than individuals who have lower affective reactivity.

\subsection{Interaction between Affective Reactivity and Affective Influence Regulation}

Even though affective reactivity and affective influence regulation are distinct characteristics, their influences on decision-making performance may not be independent if the underlying processes are systematically related to each other. Research has suggested a partial association between the intensity of feelings and its bias-inducing effect. As a result, as long as the emotional intensity is associated with decision-making, affective reactivity may influence performance in decision-making in interaction with affective influence regulation. Further, since the association is only partial, the interaction effect cannot completely replace the main effects of affective reactivity and affective influence regulation on decision-making performance. We therefore hypothesize a moderating effect of affective influence regulation on the relationship between affective reactivity and decision-making performance.

Hypothesis 3. The relationship between affective reactivity and decision-making performance is stronger for those people who have higher affective influence regulation.

\subsection{Affective Influence Regulation and Emotion Differentiation}

There is a large amount of uncertainty regarding what people should do in order to regulate the influence of their feelings on decision-making. This is so in spite of having enough scientific evidence to show that the greater the affective influence regulation, the better the decision-making performance. We now propose a way of reducing this uncertainty. Of course, we contradict the popular organizational practices that recommend people to ignore or suppress their feelings for greater affective influence regulation. In this regard, it is important to note that emotion differentiation is a key dimension on which people differ in processing emotional information. It is found that some individuals can represent their feelings in a discrete and differentiated way, whereas some people express it in an undifferentiated way over a range of interchangeable terms. The former people are characterized by small correlation among positive emotions and among negative emotions, while the latter is characterized by large positive correlations among positive emotions and among negative emotions. Several researchers have suggested that emotion differentiation is important for effective use and control of emotions, more importantly for reducing the bias-inducing effects of momentary feelings. Some researchers have suggested that greater emotion differentiation is associated with highly activated discrete emotional knowledge. They suggest as a conclusion that people having high emotion differentiation have an advantage in regulating their emotional experience and its possible negative influences on their choices and behaviors.

It is accordingly hypothesized that emotion differentiation has a positive relationship with affective influence regulation. To be more specific, people who can better identify and distinguish among their feelings are likely to better regulate the potentially bias-generating effects of their feelings an their decision-making performance. As a consequence, more emotionally differentiated people achieve higher decision-making performance by their ability to regulate their emotions in affecting their decision. Hence the following hypothesis is formulated.

Hypothesis 4. Affective influence regulation mediates the relationship between emotion differentiation and decisionmaking performance.

\section{Methods}

In order to examine the working of emotional experience and its effects on decision-making, an internet-based stock investment simulation experiment was run. This was done 


\section{International Journal of Science and Research (IJSR) ISSN (Online): 2319-7064 \\ Index Copernicus Value (2013): 6.14 | Impact Factor (2015): 6.391}

because stock investment involves a series of decisionmaking activities. In addition, this experiment also allowed isolating individual-level effects from group-level, organization-level and institution-level factors that can affect decision-making outcomes. The investment simulation was combined with an experiences-sampling procedure where investors rated their feelings and thoughts on the web site at the same time that they were performing investment activities. Momentary emotional feelings were measured multiple times to understand within-person variation in feelings.

The stock investment simulation was run for 20 business days. The participants initially had a hypothetical cash of \$ 10,000 each. There were 12 anonymous stocks to invest in. The participants logged into the stock investment simulation once a day during the simulation period. They viewed current market and stock information, checked their current investment performance and made their investment decision about which and how many shares of the 12 stocks to buy or sell for the day. At the same time, they reported their current feeling.

\subsection{Participants}

During the simulation period on every day, a 5 point scale was used to indicate the feelings of participant about each term. The five-point scale ranged from 0 indicating "not at all" to 4 indicating "extremely so." The number of terms representing affective reactivity is 18 , those representing pleasant affect items is 9 , while the number of unpleasant affect items is 9. An affective reactivity index was derived every day for every participant by taking average of the dominating affect items. Out of a total of 1868 affect reports collected, 1072 had pleasant feelings dominant and 796 had unpleasant feelings dominant. These scores were further averaged over time for every participant.

\subsubsection{Affective Influence Regulation}

An index of affective influence regulation was computed for every participant to measure the extent to which the degree pleasantness and the degree of activation influence the level of risk that a participant takes in making investment decisions. This computation involved the following steps.

Step1. The degree of pleasantness was computed by subtracting the mean of nine unpleasant items from the mean of nine pleasant items. Similarly, the degree of activation was computed by subtracting the mean of deactivated items from the mean of activated items.

Step2. Three parameters were computed from participant's daily stock investment portfolio. These three parameters are as follows. Diversification was computed as the sum squares of percentage weights invested in different stocks. A higher score indicates greater risk-taking. The average beta coefficient was calculated as the second risk indicator. The beta of a stock is a measure of volatility of the stock's price in relating to the stock market. The average of the betas indicates the risk that the participant chooses in constructing the portfolio. The average one year return the third risk indicator. The one-year return points to the level of
Six investment clubs, each having at least 40 members contacted. A total of 118 members were volunteered to participate in the stock investment simulation. Their ages ranged from 18 to 74 and 86 of the participants male. Their investment experience ranged from 0 to 50 years

\subsection{Measurement}

\subsubsection{Affective Reactivity}

A total 22 affect-related terms were selected to represent the core feeling. The terms and corresponding core feeling are tabulated below:

Table 1: Core feeling and related terms

\begin{tabular}{|c|c|}
\hline $\begin{array}{c}\text { Core feelings } \\
\text { activated feelings }\end{array}$ & $\begin{array}{c}\text { Terms used in survey } \\
\text { joyful, enthusiastic, proud, } \\
\text { interested }\end{array}$ \\
\hline $\begin{array}{c}\text { Activated feelings unpleasant } \\
\text { activated feelings }\end{array}$ & $\begin{array}{c}\text { Aroused, surprised, irritated, } \\
\text { afraid, angry, nervous, } \\
\text { frustrated }\end{array}$ \\
\hline $\begin{array}{c}\text { Unpleasant feelings } \\
\text { Unpleasant deactivated } \\
\text { feelings }\end{array}$ & $\begin{array}{c}\text { Sad, disappointed depressed, } \\
\text { tried }\end{array}$ \\
\hline $\begin{array}{c}\text { Deactivated feelings pleasant } \\
\text { deactivated feelings }\end{array}$ & Quiet, still, calm, relaxed \\
\hline
\end{tabular}

profitability and risk those participant chooses. A general index was constructed from these three as the first principal component, which explained $61 \%$ of total variance.

Step3. Two regression coefficients were computed for every participant. One of them was obtained by regressing the risk taking index on the degree of pleasantness. The other had the same risk-taking index regressed on the degree of activation over time. The absolute values of the regression coefficients were taken and one principal component explained $72 \%$ of the total variance. The scores on this principal component were used as an index of affective influence regulation.

\subsubsection{Emotion Differentiation}

Two emotion differentiation indexes were computed from the affective experience ratings. One of them was for pleasant feelings and the other was for unpleasant feelings. More details of the computations can be found in Seo and Barrett (2007). It is found that people experience more pressure to deal with their emotions when they experience negative rather than positive emotions. These two indexes, as expected were virtually uncorrelated, having $\mathrm{r}=-0.02$

\subsubsection{Decision Performance}

The average daily stock investment return was used as a measure of decision performance. The amount earned or lost by a participant was used to determine the stock investment return. This investment return was adjusted by the average performance of the 12 stocks. This was done to discourage opportunistic efforts to capitalize on stock market fluctuations.

\subsubsection{Control Variables}

Two variables that can influence the relationships among the key variables were controlled. These were the participants age and stock investment experience. Age influences emotional experience and its effects on cognitive processes. 


\section{International Journal of Science and Research (IJSR) \\ ISSN (Online): 2319-7064}

Index Copernicus Value (2013): 6.14 | Impact Factor (2015): 6.391

Experience influences emotional experience as well as decision-making performance.

\subsubsection{Procedure}

Participants visited the web site once every day. Here they got the daily stock market information and the changes and trends of a local market index. The local market index was highly correlated with national market indexes $(\mathrm{r}>0.8)$. Participants then got the daily updates information on the 12 stocks in the form of the current price, daily price change, average price for the last five days, beta coefficient, one-year stock performance, price earnings ratio, and company size. Participants then saw a report on their investment performance and expected reward so far. They were then asked to rate the different feelings according to their current emotional state. Then participants made their own investment decision for the day. The web page performed the mathematical calculations to check for any possible mistakes. At this time, the current market and stock information was also available for reference. Participants then saw their investment summary and were asked to state the reasons behind their investment decisions. Participants would $\log$ out after this step.

\subsubsection{Data Analysis}

Even though there were 118 participants in the simulation study. 108 participants completed the simulation task. They generated 2059 cases. 7 participants were dropped from the study for showing random responses and 63 more ceases were eliminated because participants reported interruptions or data transfer errors. As a result, 1870 cases, completed by 101 participants were used for the analysis.

Structural equation modeling (SEM) was used for testing the mediating and moderating effects. Several nested models were fitted using SEM. Model-fit Was assessed using (1) Chi-square goodness-of-fit statistic, (2) root-mean-square error (RMSE), (3) goodness-of-fit index (GFI), (4) adjusted goodness-of-fit index (AGFI), (5) normal fit index (NFI) and (6) comparative fit index (CFI).

\section{Results}

The mean, standard deviation, minimum, maximum and correlation coefficient with every other variable is given in Table 2

Table 2: Means, Standard Deviations, and Correlations ${ }^{\mathrm{a}}$

\begin{tabular}{|l|r|r|r|r|r|r|r|r|c|c|}
\hline \multicolumn{1}{|c|}{ Variable } & Mean & \multicolumn{1}{c|}{ S.d. } & Maximum & Minimum & 1 & 2 & 3 & 4 & 5 & 6 \\
\hline Age in years & 25.05 & 13.63 & 74 & 18 & & & & & & \\
\hline Experience in months & 52.96 & 90.97 & 600 & 0 & $.77^{* *}$ & & & & & \\
\hline Decision performance & -0.46 & 2.50 & 7.87 & -7.42 & $-.21^{*}$ & -.07 & & & & \\
\hline Affective reactivity & 1.41 & 0.57 & 3.49 & 0.33 & -.16 & -.01 & $.23^{*}$ & & & \\
\hline Affective influence regulation & 0.00 & 1.00 & 0.85 & -6.38 & -.19 & -.10 & $.27^{* *}$ & .02 & & \\
\hline Positive emotion differentiation & 0.70 & 0.20 & 1.23 & 0.14 & .09 & .11 & .04 & $.20^{*}$ & .12 & \\
\hline Negative emotion differentiation & 0.69 & 0.27 & 1.16 & 0.02 & .01 & .04 & -.14 & $-.23^{*}$ & $.23^{*}$ & .02 \\
\hline
\end{tabular}

${ }^{a} \mathrm{n}=101$.

$* \mathrm{p}<.05$

$* * \mathrm{p}<.01$

\subsection{The basic model and testing the main effects.}

The basic hypothesis specifies the primary relationships among the key variables. This model directly involves the two main effects through hypothesis 1 and 2 . The moderation effect is tested through hypothesis 3 , while the mediation effect is tested through hypothesis 4 .

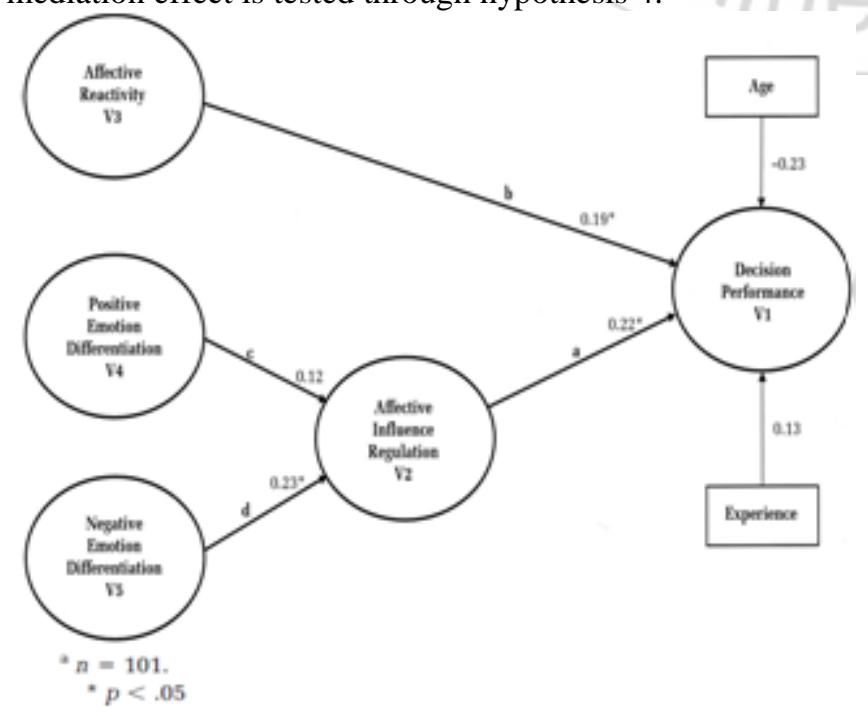

Figure 1: Basic Hypothesized Path Model with Standardized Path Coefficients ${ }^{\mathrm{a}}$
Figure 1 shows the four main paths to be estimated. Each path corresponds to one of the hypotheses. Figure 1 also shows estimates of standardized path coefficients. The results of SEM showed that the model fitted well, as indicated by the following.
1) Chi-square $=7.43, \mathrm{df}=5, \mathrm{p}<0.19$
2) $\mathrm{GFI}=0.98$
3) $\mathrm{AGFI}=0.89$
4) $\mathrm{RMSE}=0.07$
5) $\mathrm{CFI}=0.98$
6) $\mathrm{NFI}=0.95$

The path coefficient from affective influence regulation to decision performance was $\mathrm{b}=0.56, \mathrm{t}=2.40, \mathrm{p}<0.05$, and supported hypothesis 1 . The path coefficient from affective reactivity to decision performance was $\mathrm{b}=0.85, \mathrm{t}=2.01, \mathrm{p}<$ 0.05 and supported hypothesis 2 .

\subsection{Moderation Effect}

Hypothesis 3 was tested with help of a moderation model developed by adding an interaction term between affective reactivity and affective influence regulation and a direct path was specified from this interaction term to decision performance. The SEM got the following results for the moderation model. 


\section{International Journal of Science and Research (IJSR) \\ ISSN (Online): 2319-7064}

Index Copernicus Value (2013): 6.14 | Impact Factor (2015): 6.391

1) Chi-square $=13.41, \mathrm{df}=9, \mathrm{p}<0.15$

2) $\mathrm{GFI}=0.97$

3) $\mathrm{AGFI}=0.87$

4) $\mathrm{RMSE}=0.07$

5) $\mathrm{CFI}=0.97$

6) $\mathrm{NFI}=0.93$

However, the path coefficient of the interaction terms was $b$ $=-0.01, \mathrm{t}=-0.05$, showing that hypothesis 3 was not supported. This was interpreted to imply that affective reactivity and affective influence regulation contribute to decision performance additively, and not interactively.

\subsection{Mediation Effect}

Hypothesis 4 states that affective influence regulation mediates the relationship between emotion differentiation and decision performance. It was tested by developing an appropriate model. The results of SEM show that the path coefficient from positive emotion differentiation to affective influence regulation is not significant, but the path coefficient from negative emotion differentiation to affective influence regulation is positive and significant. The conclusion is that participants who can differentiate negative emotions are less influenced by their emotional feelings in determining the level of risk in their daily stock portfolio.

Two new models were developed at this point of time. One was a partial mediation model and the other was a non mediated model. The SEM results suggest that the partial mediation model fit the data well, but does not differ significantly from the hypothesized model. The non mediated model did not fit the data well.

\section{Discussion and Conclusion}

The popular belief in decision theory that "cooler head prevails" is contradicted by the findings of this study. The study evidently shows that feelings and emotions can have positive effects on decision performance. In particular, people who experienced their feelings with greeter intensity achieved higher decision performance. Another popular belief, namely "Don't let your emotions run your life," was supported by the study showing that people who could keep their feelings from having direct impact on their decisions achieved higher decision performance. The popular regulation "Ignore your emotions" appears not to be the right answer for effective regulation of feelings and their influence on decision-making.

Feelings are an indispensable part of life and are powerful enough to influence (both benefit and harm) choices and decisions. It is important to understand the role of emotions in decision-making and more research in this area must be welcome.

\section{References}

[1] Ashforth, B. E., \& Humphrey, R. H. 1995. Emotion in the workplace: A reappraisal. Human Relations, 48: 97125.
[2] Aspinwall, L. G., \& Taylor, S. E. 1997. A stitch in time: Self-regulation and proactive coping. Psychological Bulletin, 121: 417-436.

[3] Babin, C. E., \& Donovan, W. J. 2000. Investing secrets of the masters: Applying classical investment ideas to today's turbulent markets. New York: McGraw Hill.

[4] Damasio, A. R. 1994. Descartes' error: Emotion, reason, and the human brain. New York: Avon Books.

[5] Forgas, J. P. 2000. Managing moods: Towards a dualprocess theory of spontaneous mood regulation. Psychological Inquiry, 11: 172-177.

[6] Forgas, J. P., \& Ciarrochi, J. V. 2002. On managing moods: Evidence for the role of home static cognitive strategies in affect regulation. Personality and Social Psychological Bulletin, 28: 336-345.

[7] Gohm, C. L., \& Clore, G. L. 2002. Affect as information: An individual-difference approach. In L. Barrett \& P. Salovey (Eds.), The wisdom of feeling: Psychological processes in emotional intelligence: 89 113. New York: Guilford Press.

[8] Gross, J. J., \& John, O. P. 2003. Individual differences in two emotion regulation processes: Implications for affect, relationships, and well-being. Journal of Personality and Social Psychology, 85: 348-362.

[9] Hochschild, A. R. 1983. The managed heart. Berkeley: University of California Press.

[10] Larsen, R. J. 2000. Toward a science of mood regulation. Psychological Inquiry, 11: 129-141.

[11] Morris, J. A., \& Feldman, D. C. 1996. The dimensions, antecedents, and consequences of emotional labor. Academy of Management Review, 21: 986-1010.

[12] Myeong Seo and Lisa Feldman Barrett (2007). Being emotional during decision making - good or bad? An empirical investigation. Academy of management Journal, vol. 50, No. 4, pp. 923-940

[13] Putnam, L. L., \& Mumby, D. K. 1993. Organizations, emotion and the myth of rationality. In S. Fineman (Ed.), Emotion in organization: 36-57. London: Sage.

[14] Seo, M. and Barrett, L. F. (2007). Being Emotional During Decision Making - Good or Bad? An Empirical Investigation. Academy of Management Journal, Vol. 50, No. 4, pp. 923 - 940.

[15] Shiv, B., Loewenstein, G., Bechara, A., Damasio, H., \& Damasio, A. R. 2005. Investment behavior and the negative side of emotion. Psychological Science, 16: 435-439.

[16] Slovic, P. 2001. Psychological study of human judgment: Implications for investment decision making. Journal of Psychology and Financial Markets, 2: $160-$ 172.

[17] Slovic, P., Finucane, M., Peters, E., \& MacGregor, D. G. 2002. The affect heuristic. In G. D. Griffin \& D. Kahneman (Eds.), Intuitive judgment: Heuristics and biases: 397-420. New York: Cambridge University Press. 